\title{
Optimizing visualization in enhanced depth imaging OCT in healthy subjects and patients with retinal pigment epithelial detachment
}

This article was published in the following Dove Press journal:

Clinical Ophthalmology

20 November 2012

Number of times this article has been viewed

Lukas Reznicek

Efstathios Vounotrypidis

Florian Seidensticker

Karsten Kortuem

Anselm Kampik

Aljoscha S Neubauer

Armin Wolf

Department of Ophthalmology, Ludwig Maximilians University

Muenchen, Munich, Germany
Correspondence: Lukas Reznicek Ludwig-Maximilians-University, Department of Ophthalmology, Klinikum der Universität München, Campus Innenstadt, Mathildenstrasse 8, D-80336

Munich, Germany

Tel +4989516038II

$\mathrm{Fax}+49$ 913। 51603051

Email lukas.reznicek@med.uni-

muenchen.de
Background: This study's objective was to optimize the visualization of three different spectral-domain optical coherence tomography (SD-OCT) display modalities and evaluate enhanced depth imaging (EDI) by comparing the maximum depth of assessment in conventional versus inverted cross-sectional OCT images in healthy subjects and in patients with retinal pigment epithelial detachment (PED).

Methods: Cross-sectional SD-OCT conventional and inverted images were obtained with the HRA2 (Heidelberg Retina Angiograph II, Heidelberg Engineering, Heidelberg, Germany). Horizontal as well as vertical sections in three different display modes were blinded for evaluation by three independent, experienced graders for maximal imaging depth of the deep ocular fundus layers.

Results: The mean imaging depth as measured from the inner segment/outer segment (IS/OS) to the outer choroid of all 14 healthy subjects was $197 \pm 44 \mu \mathrm{m}$ vs $263 \pm 56 \mu \mathrm{m}$ for conventional vs EDI scans: in black/white mode, it was significantly lower $(P<0.001)$ than in white/black mode $(249 \pm 42 \mu \mathrm{m}$ vs $337 \pm 71 \mu \mathrm{m})$ and color/heat mode $(254 \pm 48 \mu \mathrm{m}$ vs $354 \pm 73 \mu \mathrm{m})$. The mean imaging depth of all 14 study eyes with PED was $240 \pm 78 \mu \mathrm{m}$ vs $345 \pm 100 \mu \mathrm{m}$ for conventional vs EDI scans in black/white mode, and was significantly lower $(P<0.001)$ than in white/black mode ( $393 \pm 104 \mu \mathrm{m}$ vs $464 \pm 126 \mu \mathrm{m})$ and in color/heat mode ( $373 \pm 106 \mu \mathrm{m}$ vs $453 \pm 114 \mu \mathrm{m}$ ). In each display modality of healthy subjects and of patients with PED, EDI scans showed a significantly higher imaging depth than the corresponding conventional scans.

Conclusion: White/black and color/heat modes allow increased imaging depth, compared to black/white mode using both conventional or EDI OCT scans in healthy subjects or patients with PED. EDI obtained with HRA2 significantly improves the imaging depth, compared to conventional OCT scans.

Keywords: OCT, EDI OCT, enhanced depth imaging, pigment epithelial detachment, imaging mode, optical coherence tomography

\section{Introduction}

Optical coherence tomography (OCT) is becoming more relevant for ophthalmic diagnostics and is increasingly used for therapy. ${ }^{1-10}$ Imaging speed and quality have greatly improved over the last few years. ${ }^{11-15}$

Over the past two decades, the focus has been predominantly on diseases with retinal or vitreoretinal pathology, such as diabetic retinopathy, macular edema, age-related macular degeneration, vitreomacular traction syndrome, and macular holes, imaging of the choroid has gained increasing attention. Ocular diseases of the posterior pole, such as myopia, pseudoxanthoma elasticum, retinal pigment epithelial detachment, central serous retinopathy, Vogt-Koyanagi-Harada disease, and retinal dystrophies, 
were shown to have alterations of the choroid that could be visualized and evaluated using the noninvasive, enhanced depth imaging (EDI) OCT technique. ${ }^{16-21}$

Increased penetration depth for a better evaluation of the choroid can be achieved either by using laser sources with a higher wavelength compared to the commonly used Spectralis $^{\circledR}$ OCT with $870 \mathrm{~nm}$ (Heidelberg Engineering, Heidelberg, Germany) or, alternatively, to manually inverting the image obtained in vivo or using the recently available automatic EDI-module in the Spectralis ${ }^{\circledR}$ OCT HRA2. ${ }^{19,22-25}$ Measurements of the choroid obtained with enhanced depthimaging protocols using a variety of OCT devices have a high reproducibility among healthy patients. ${ }^{26,27}$

However, subretinal pathologies with significant signal attenuation due to thickening or high absorption of the emitted light, as for example in pigment epithelial detachment (PED), are still a challenge for OCT imaging.

The purpose of our study was to optimize the visualization of three different SD-OCT display modalities of conventional versus inverted (EDI) cross-sectional OCT images by comparing the maximum depth of assessment in healthy subjects with that in patients with PED.

\section{Methods}

\section{Patients}

A consecutive series of 14 eyes of healthy subjects, mean age $31 \pm 5$ years, and 14 eyes diagnosed with PED due to AMD, mean age $74 \pm 10$ years, were included in this study. Exclusion criteria for healthy subjects were any retinal pathologies or media opacities and for patients with PED previous focal laser treatment of the macula, PED due to choroidal or suprachoroidal tumors, or significant media opacities. After informed consent, a full retinal examination was performed by a retinal specialist, followed by OCT imaging. All research was conducted in accordance with institutional guidelines and board approval, and conformed to the tenets of the World Medical Association Declaration of Helsinki.

\section{SD-OCT images}

All patients were imaged with conventional and enhanced depth-image cross-sectional scans by a Heidelberg Spectralis ${ }^{\circledR}$ OCT (Heidelberg Engineering) with an excitation wavelength of $870 \mathrm{~nm}$ and a scanning speed of 40,000 A-scans per second. The axial resolution was $\sim 6 \mu \mathrm{m}$, compared to a lateral resolution of $14 \mu \mathrm{m}$. EDI was performed by positioning the SD-OCT closer to the eye in order to generate an inverted image on the top of the computer display. A possible physical explanation for EDI may be a decreased delay in light wavelengths returning from the depicted subretinal structures that are further away from the zero delay line; this is detected by the interferometer and compared to the light wavelengths of the reference arm, the final result of which is a better signal intensity of the imaged deeper layers of the posterior fundus. ${ }^{25} \mathrm{~A}$ horizontal and vertical OCT image was obtained through the fovea, each comprised of 15 averaged scans, using the automatic-averaging and eye-tracking features of the Heidelberg Spectralis ${ }^{\circledR}$ OCT. Acquisition of the crosssectional scans was obtained together with an infrared, realtime fundus image, which allowed point-to-point correlation between the fundus images and the OCT cross-sectional scans. The same modality with a horizontal and vertical cross-sectional scan was used to obtain conventional scans for comparison.

\section{Image analysis}

Quantitative analysis of the obtained horizontal and vertical SD-OCT cross-sectional scans of each study eye was performed using Image $\mathrm{J}$ software $(\mathrm{NIH}$, available at http://rsb.info.nih.gov). Before evaluating the images, the inverted scans were processed to obtain upright images allowing blinded evaluation. The largest possible distance from the inner-segment/outer-segment band (IS/OS) to the farthest discernible structure was measured in each conventional and inverted image in the black/white mode, white/black mode, and color/heat mode display modalities (Figure 1) of each horizontal and vertical cross-sectional scan obtained. All measurements of each eye were successively obtained and graded by three blinded, independent,
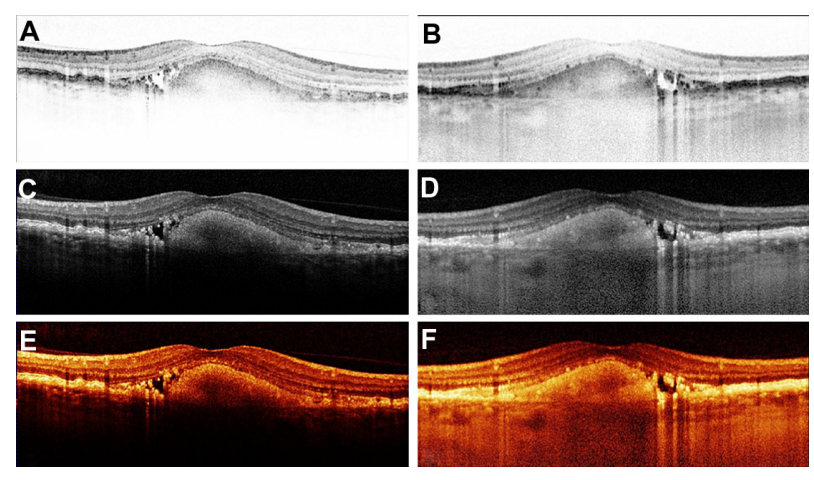

Figure I Vertical cross-sectional scan of the left eye through the fovea of a 66-year-old female patient displaying a central fibrovascular pigment epithelial detachment. The display modalities are black/white mode in (A) (conventional) and (B) (enhanced depth imaging); white/black mode in (C) (conventional) and (D) (enhanced depth imaging); and color/heat mode in (E) (conventional) and (F) (enhanced depth imaging). Inverted scans (B, D, and F) show an increased imaging depth of the choroid in all three different display modalities, compared to the conventional scans. 
experienced graders on 22-inch TFT displays (Flatron; maximal resolution $1680 \times 1050$ pixels, brightness $250 \mathrm{~cd} / \mathrm{m}^{2}$; LG Corp, Seoul, South Korea) using the same measurement scale. Mean values from each graders' measurements of the horizontal and vertical scans were calculated for each of the three display modalities.

\section{Statistical analysis}

Data were collected and analyzed using SPSS Version 17.0 (IBM Corporation, Armonk, NY). A $P$-value of $<0.05$ was considered statistically significant. The interobserver reproducibility values were evaluated based on the intraclass correlation coefficient according to Shrout and Fleiss. ${ }^{28}$ Nonparametric analyses (Wilcoxon signed-ranks test) were applied and adjusted for multiple testing by applying the Bonferroni adjustment.

\section{Results}

The overall interobserver reliability for each measurement and for each display modality between all three independent graders was very high and statistically significant, with a Kronbach's alpha of $0.888(0.822-0.950 ; P<0.001)$.

The mean imaging depth of all 14 healthy subjects was $197 \pm 44 \mu \mathrm{m}$ vs $263 \pm 56 \mu \mathrm{m}$ for conventional vs EDI scans in black/white mode, and was significantly lower $(P<0.001)$ than in the white/black mode, with $249 \pm 42 \mu \mathrm{m}$ vs $337 \pm 71 \mu \mathrm{m}$, and than in the color/heat mode, with $254 \pm 48 \mu \mathrm{m}$ vs $354 \pm 73 \mu \mathrm{m}$ (Figures 2 and 3 ).

Fourteen eyes with PED met the inclusion criteria for this group. Of those, five had serous PEDs and eight

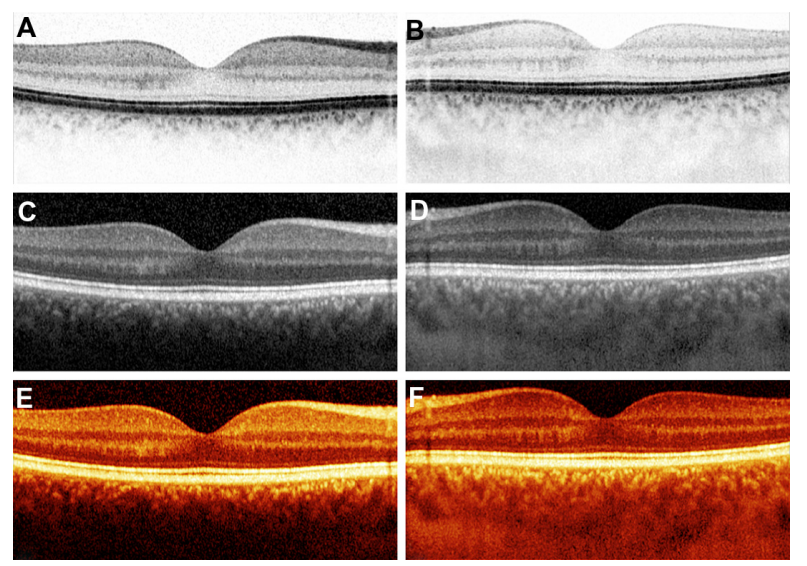

Figure 2 Vertical cross-sectional scan of the right eye through the fovea of a 27-year-old male healthy subject. The display modalities are black/white mode in (A) (conventional) and (B) (enhanced depth imaging); white/black mode in (C) (conventional) and (D) (enhanced depth imaging); and color/heat mode in (E) (conventional) and (F) (enhanced depth imaging). Inverted scans (B, D, and F) show an increased imaging depth of the choroid in all three different display modalities, compared to the conventional scans.

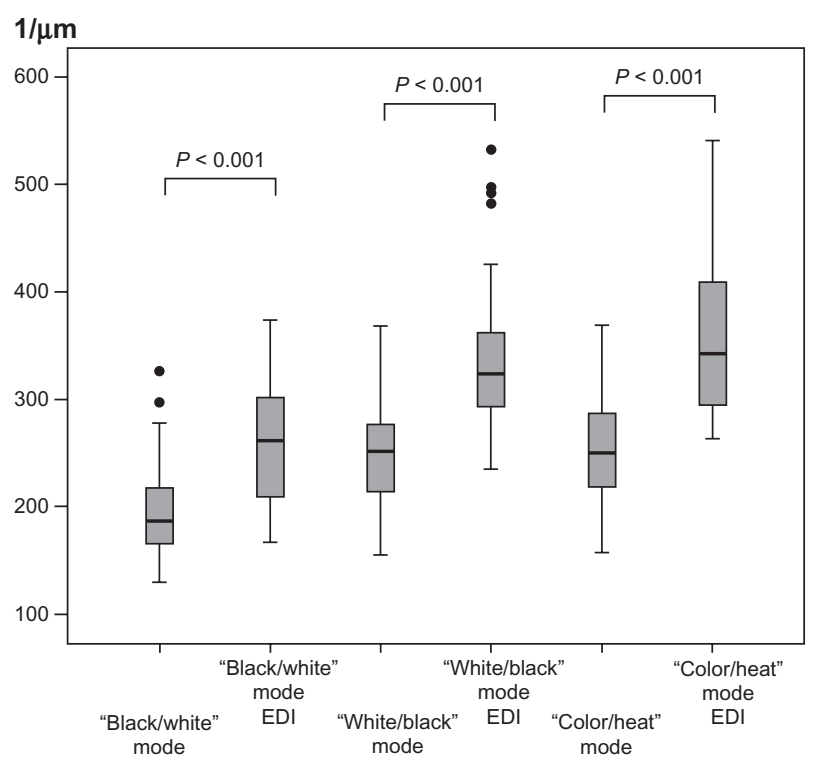

Figure 3 Mean imaging depth of conventional compared to enhanced depth imaging (EDI) optical coherence tomography scans in three different display modalities of all 14 healthy subjects with pigment epithelial detachment obtained by three independent graders.

had fibrovascular PEDs, as determined by OCT findings. Imaging artifacts and disruption of OCT signal increased with the height and amount of nonserous content of the PED. The mean imaging depth of all 14 eyes with PED was $240 \pm 78 \mu \mathrm{m}$ vs $345 \pm 100 \mu \mathrm{m}$ for conventional vs EDI scans in black/white mode, which was significantly lower $(P<0.001)$ than in white/black mode $(393 \pm 104 \mu \mathrm{m}$ vs $464 \pm 126 \mu \mathrm{m})$ and in color/heat mode ( $373 \pm 106 \mu \mathrm{m}$ vs $453 \pm 114 \mu \mathrm{m})$. In each display modality of healthy subjects and patients with PED, EDI scans showed a significantly higher imaging depth than did the corresponding conventional scans.

A statistically significant different maximum depth of imaging was found between conventional and EDI scans and their particular display modes by applying the Friedman test for nonparametrical variables, with $\chi^{2}=158.724, P=0.000$ for healthy subjects and $\chi^{2}=138.190, P<0.001$ for patients with PED. Post hoc analysis with the Bonferroni adjustment $(P<0.017)$ of the Wilcoxon signed-ranks test revealed a significant difference between conventional and EDI scans for healthy subjects and patients with PED, respectively, in each evaluated mode: black/white mode $(Z=-5.545$, $P<0.001$ and $\mathrm{Z}=-5.208, P<0.001)$; white/black mode ( $\mathrm{Z}=-5.458, P<0.001$ and $\mathrm{Z}=-4.620, P<0.001)$; and color/heat mode $(\mathrm{Z}=-5.570, P<0.001$ and $\mathrm{Z}=-4.739$, $P<0.001$ ) (Figures 4 and 5).

A statistically significant difference was also observed between black/white and white/black mode, as well as between black/white and color/heat mode. This was true for both types 


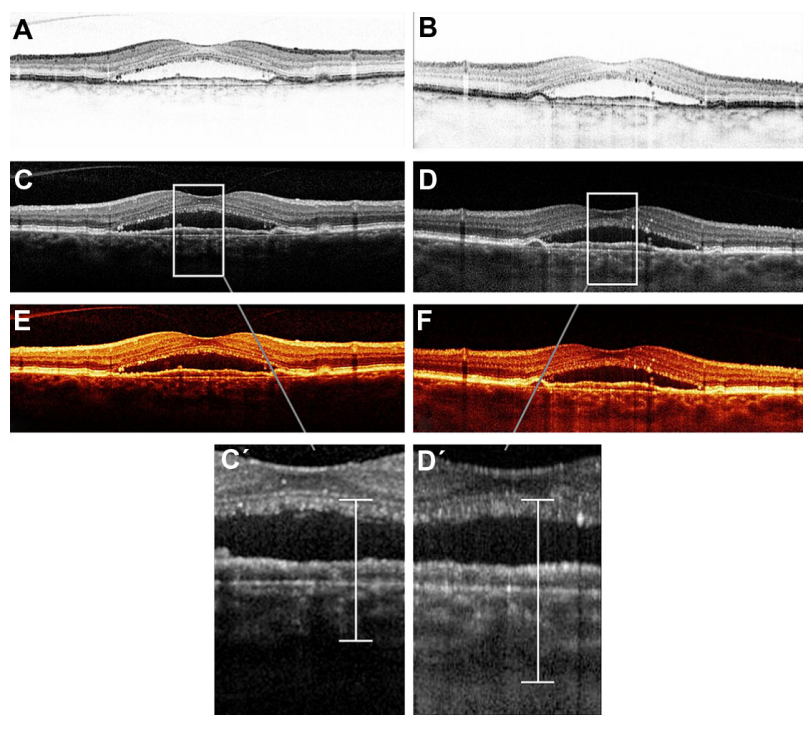

Figure 4 Vertical cross-sectional scan of the left eye through the fovea of a 79-year-old female patient displaying a central mainly serous pigment epithelial detachment. The display modalities are black/white mode in (A) (conventional) and (B) (enhanced depth imaging); white/black mode in (C) (conventional) and (D) (enhanced depth imaging); and color/heat mode in (E) (conventional) and (F) (enhanced depth imaging). Inverted scans (B, D, and F) show an increased imaging depth through the subretinal serous fluid compared to the conventional scans, shown in ( $\mathbf{C}^{\prime}$ and $\left.\mathbf{D}^{\prime}\right)$.

of conventional and EDI scans for healthy subjects $(Z=-5.620$, $P<0.001$ and $\mathrm{Z}=-5.620, P<0.001)$ as well as for patients with $\operatorname{PED}(Z=-5.495, P<0.001$ and $Z=-5.645, P<0.001)$. It was also true for EDI scans of healthy subjects $(Z=-5.449$, $P<0.001$ and $\mathrm{Z}=-5.558, P<0.001)$ and 1 for patients with $\operatorname{PED}(\mathrm{Z}=-5.495, P<0.001$ and $\mathrm{Z}=-5.645, P<0.001)$.

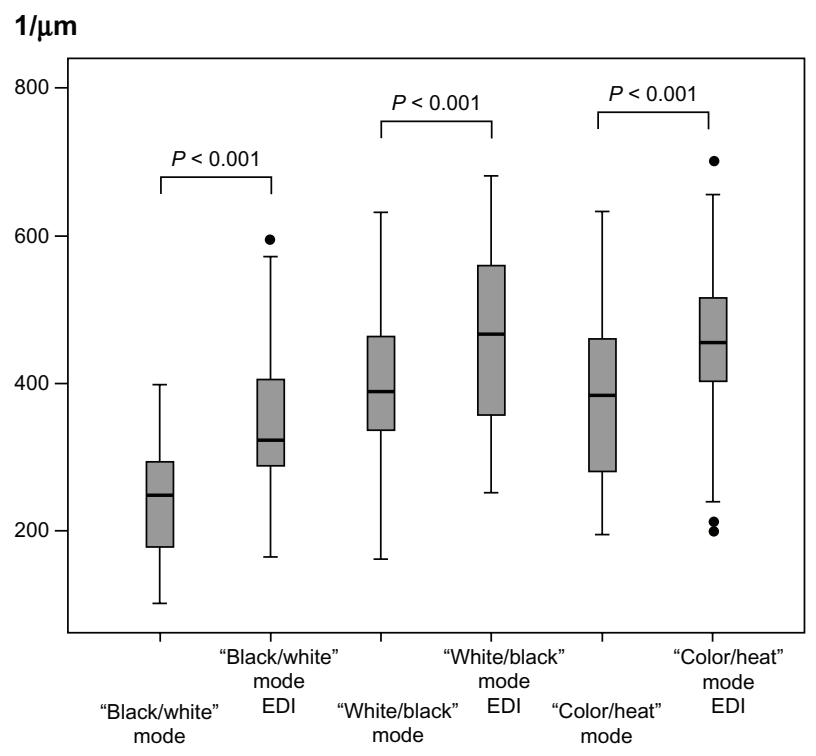

Figure 5 Mean imaging depth of conventional compared to enhanced depth imaging (EDI) optical coherence tomography scans in three different display modalities of all 14 study eyes with pigment epithelial detachment obtained by three independent graders.

\section{Discussion}

In our study, the depth of obtained OCT scans was, as expected, larger in EDI mode than in conventional imaging mode. This was true for all display modalities and was observable in healthy individuals and in patients with PED.

OCT EDI was introduced in 2008 and has become increasingly popular for imaging the choroid. ${ }^{25}$ Enhanced depth images of patients with PED allow us to examine the internal structure of PED presenting with serous or fibrovascular content. ${ }^{19}$

OCT signal strength decreases as light penetrates tissue and is back-reflected or scattered. In addition, using spectraldomain OCT, signal strength inherently decreases on the OCT image as the point of interest moves away from the zero delay line (typically placed at the top of the OCT image). ${ }^{25,29,30}$

PED, with its increased retinal and/or choroidal thickness, presents a challenge for imaging deeper structures based upon the physical principles mentioned above. Therefore, in addition to assessing visualization in healthy subjects, we have chosen eyes with PED to evaluate and optimize the maximum imaging depth of different modes in conventional and EDI imaging.

The observed increase of imaging depth for inverted vs conventional OCT scans, not only in healthy subjects but also in patients with PED, supports the concept of enhancing signal sensitivity by inverting the image and intentionally focusing upon the deeper layers.

Interestingly, we found an increased imaging depth in white/black mode or color/heat mode compared to black/ white mode, both in healthy subjects and in patients with PED. This might be explained by varying distinct softwarerelated contrast discrimination between the evaluated display modalities (black/white, white/black and color/heat) of the same cross-sectional scan. The observed display modality differences showed similar tendencies in conventional and inverted OCT scans.

Our results from the second group of patients are restricted to the specific pathology of PED. The heterogenous internal structures, including blocking phenomena in overlying retinal layers, can be subdivided into serous and fibrovascular PED, which results in varying imaging depths with differing decreases in signal intensity. This heterogeneity can be seen in the relatively large confidence intervals of mean measurements within a particular modality (see Figure 3). Nonetheless, there was a convincing consistency among the three independent graders (high interobserver reliability of 0.914 ). In our study, six out of 14 eyes had serous PED and eight had fibrovascular PED, with significant decrease in signal intensity observed predominantly in the fibrovascular 
subtype that did not allow for imaging the full thickness of the choroid. Therefore, alternative OCT devices with a better penetration through the retinal pigment epithelium using laser sources with higher wavelengths may be more suitable for choroidal imaging in the setting of PED. ${ }^{31-33}$

To achieve statistical reliability, the maximum imaging depth for each of the 28 eyes included in the study was measured by three independent graders for each of the three display modalities (scanning horizontally and vertically, cross-sectionally, and by type - conventional or EDI), resulting in 36 measurements per eye and 1008 measurements for all 28 eyes included.

In conclusion, the two display modalities - white/black mode and color/heat mode - allow increased imaging depth, compared to the black/white mode using the HRA2 for both conventional and EDI OCT scans in patients with PED. Nonetheless, deeper-structure EDI still presents a challenge. EDI obtained with HRA2 significantly improves the imaging depth, compared to conventional OCT scans.

\section{Disclosure}

The authors report no conflicts of interest in this work, including any commercial interest in any of the materials and methods used in this study.

\section{References}

1. Huang D, Swanson EA, Lin CP, et al. Optical coherence tomography. Science. 1991;254:1178-1181.

2. Landa G, Su E, Garcia PM, Seiple WH, Rosen RB. Inner segment-outer segment junctional layer integrity and corresponding retinal sensitivity in dry and wet forms of age-related macular degeneration. Retina. 2011;31:364-370.

3. Neubauer AS, Priglinger SG, Thiel MJ, May CA, Welge-Lussen UC. Sterile structural imaging of donor cornea by optical coherence tomography. Cornea. 2002;21:490-494.

4. Qiu KL, Zhang MZ. The effect of image quality on retinal nerve fiber layer measurement in Stratus OCT. Am J Ophthalmol. 2011;151:384; author reply 384-385.

5. Reznicek L, Kernt M, Haritoglou C, Kampik A, Ulbig M, Neubauer AS. In vivo characterization of ischemic retina in diabetic retinopathy. Clin Ophthalmol. 2010;5:31-35.

6. Binder S, Falkner-Radler CI, Hauger C, Matz H, Glittenberg C. Feasibility of intrasurgical spectral-domain optical coherence tomography. Retina. 2011;31:1332-1336.

7. Brown DM, Kaiser PK, Michels M, et al. Ranibizumab versus verteporfin for neovascular age-related macular degeneration. $N$ Engl J Med. 2006;355:1432-1444.

8. Clark ME, McGwin G Jr, Neely D, et al. Association between retinal thickness measured by spectral-domain optical coherence tomography (OCT) and rod-mediated dark adaptation in non-exudative age-related maculopathy. Br J Ophthalmol. 2011;95:1427-1432.

9. Fung AE, Lalwani GA, Rosenfeld PJ, et al. An optical coherence tomography-guided, variable dosing regimen with intravitreal ranibizumab (Lucentis) for neovascular age-related macular degeneration. Am J Ophthalmol. 2007;143:566-583.
10. Witkin AJ, Vuong LN, Srinivasan VJ, et al. High-speed ultrahigh resolution optical coherence tomography before and after ranibizumab for agerelated macular degeneration. Ophthalmology. 2009;116:956-963.

11. Gorczynska I, Srinivasan VJ, Vuong LN, et al. Projection OCT fundus imaging for visualising outer retinal pathology in non-exudative agerelated macular degeneration. Br J Ophthalmol. 2009;93:603-609.

12. Ho J, Witkin AJ, Liu J, et al. Documentation of intraretinal retinal pigment epithelium migration via high-speed ultrahigh-resolution optical coherence tomography. Ophthalmology. 2011;118:687-693.

13. Serbecic N, Beutelspacher SC, Aboul-Enein FC, Kircher K, Reitner A, Schmidt-Erfurth U. Reproducibility of high-resolution optical coherence tomography measurements of the nerve fibre layer with the new Heidelberg Spectralis optical coherence tomography. Br JOphthalmol. 2011;95:804-810.

14. Srinivasan VJ, Adler DC, Chen Y, et al. Ultrahigh-speed optical coherence tomography for three-dimensional and en face imaging of the retina and optic nerve head. Invest Ophthalmol Vis Sci. 2008;49:5103-5110.

15. Wolf-Schnurrbusch UE, Ceklic L, Brinkmann CK, et al. Macular thickness measurements in healthy eyes using six different optical coherence tomography instruments. Invest Ophthalmol Vis Sci. 2009;50:3432-3437.

16. Fong AH, Li KK, Wong D. Choroidal evaluation using enhanced depth imaging spectral-domain optical coherence tomography in VogtKoyanagi-Harada disease. Retina. 2011;31:502-509.

17. Fujiwara T, Imamura Y, Margolis R, Slakter JS, Spaide RF. Enhanced depth imaging optical coherence tomography of the choroid in highly myopic eyes. Am J Ophthalmol. 2009;148:445-450.

18. Ari Yaylali S, Erbil HH, Salar S, Karakurt Y. Optical coherence tomography findings in pseudoxanthoma elasticum. Eur J Ophthalmol. 2010;20:397-401.

19. Spaide RF. Enhanced depth imaging optical coherence tomography of retinal pigment epithelial detachment in age-related macular degeneration. Am J Ophthalmol. 2009;147:644-652.

20. Imamura Y, Fujiwara T, Margolis R, Spaide RF. Enhanced depth imaging optical coherence tomography of the choroid in central serous chorioretinopathy. Retina. 2009;29:1469-1473.

21. Yeoh J, Rahman W, Chen F, et al. Choroidal imaging in inherited retinal disease using the technique of enhanced depth imaging optical coherence tomography. Graefes Arch Clin Exp Ophthalmol. 2010;248:1719-1728.

22. Povazay B, Bizheva K, Hermann B, et al. Enhanced visualization of choroidal vessels using ultrahigh resolution ophthalmic OCT at 1050 nm. Opt Express. 2003;11:1980-1986.

23. Lee EC, de Boer JF, Mujat M, Lim H, Yun SH. In vivo optical frequency domain imaging of human retina and choroid. Opt Express. 2006;14:4403-4411.

24. Esmaeelpour M, Povazay B, Hermann B, et al. Three-dimensional 1060-nm OCT: choroidal thickness maps in normal subjects and improved posterior segment visualization in cataract patients. Invest Ophthalmol Vis Sci. 2010;51:5260-5266.

25. Spaide RF, Koizumi H, Pozzoni MC. Enhanced depth imaging spectral-domain optical coherence tomography. Am J Ophthalmol. 2008;146:496-500.

26. Rahman W, Chen FK, Yeoh J, Patel P, Tufail A, Da Cruz L. Repeatability of manual subfoveal choroidal thickness measurements in healthy subjects using the technique of enhanced depth imaging optical coherence tomography. Invest Ophthalmol Vis Sci. 2011;52:2267-2271.

27. Branchini L, Regatieri CV, Flores-Moreno I, Baumann B, Fujimoto JG, Duker JS. Reproducibility of choroidal thickness measurements across three spectral domain optical coherence tomography systems. Ophthalmology. 2012;119:119-123.

28. Shrout PE, Fleiss JL. Intraclass correlations: uses in assessing rater reliability. Psychol Bull. 1979;86:420-428.

29. An L, Wang RK. Use of a scanner to modulate spatial interferograms for in vivo full-range Fourier-domain optical coherence tomography. Optics letters. 2007;32:3423-3425. 
30. Wang RK. Fourier domain optical coherence tomography achieves full range complex imaging in vivo by introducing a carrier frequency during scanning. Phys Med Biol. 2007;52:5897-5907.

31. Eigenwillig CM, Klein T, Wieser W, Biedermann BR, Huber R. Wavelength swept amplified spontaneous emission source for high speed retinal optical coherence tomography at $1060 \mathrm{~nm}$. J Biophotonics. 2011;4:552-558.
32. Klein T, Wieser W, Eigenwillig CM, Biedermann BR, Huber R. Megahertz OCT for ultrawide-field retinal imaging with a $1050 \mathrm{~nm}$ Fourier domain mode-locked laser. Opt Express. 2011;19:3044-3062.

33. Esmaeelpour M, Povazay B, Hermann B, et al. Mapping choroidal and retinal thickness variation in type 2 diabetes using three-dimensional 1060-nm optical coherence tomography. Invest Ophthalmol Vis Sci. 2011;52:5311-5316.

\section{Publish your work in this journal}

Clinical Ophthalmology is an international, peer-reviewed journal covering all subspecialties within ophthalmology. Key topics include: Optometry; Visual science; Pharmacology and drug therapy in eye diseases; Basic Sciences; Primary and Secondary eye care; Patient Safety and Quality of Care Improvements. This journal is indexed on

\section{Dovepress}

PubMed Central and CAS, and is the official journal of The Society of Clinical Ophthalmology (SCO). The manuscript management system is completely online and includes a very quick and fair peer-review system, which is all easy to use. Visit http://www.dovepress.com/ testimonials.php to read real quotes from published authors. 